\title{
Fluctuating selection across years and phenotypic variation in food-deceptive orchids
}

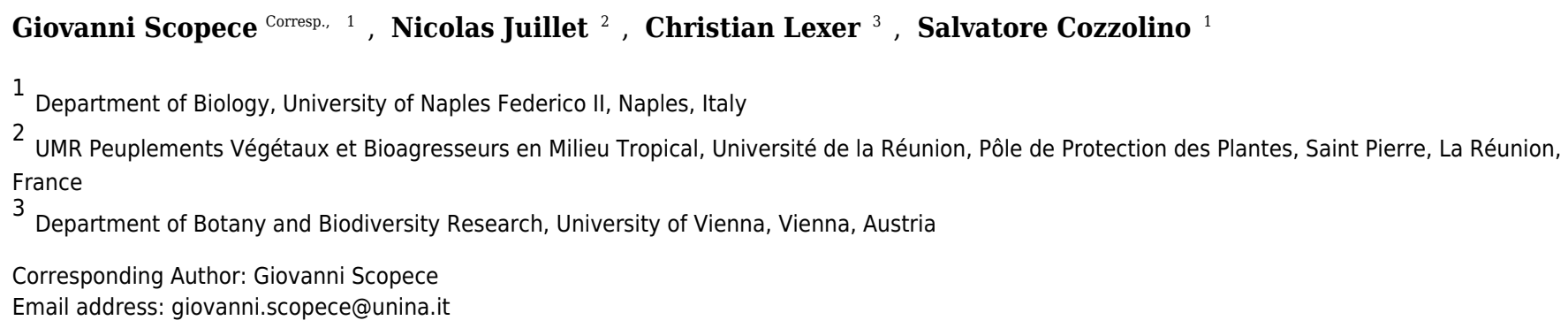

Nectarless flowers that deceive pollinators offer an opportunity to study asymmetric plantinsect interactions. Orchids are a widely used model for studying these interactions because they encompass several thousand species adopting deceptive pollination systems. High levels of intra-specific phenotypic variation have been reported in deceptive orchids, suggesting a reduced consistency of pollinator-mediated selection on their floral traits. Nevertheless, several studies report on widespread directional selection mediated by pollinators even in these deceptive orchids. In this study we test the hypothesis that the observed selection can fluctuate across years in strength and direction thus likely contributing to the phenotypic variability of this orchid group. We performed a three-year study estimating selection differentials and selection gradients for nine phenotypic traits involved in insect attraction in two Mediterranean orchid species, namely Orchis mascula and $O$. pauciflora, both relying on a well-described food-deceptive pollination strategy. We found weak directional selection and marginally significant selection gradients in the two investigated species with significant intra-specific differences in selection differentials across years. Our data do not link this variation with a specific environmental cause, but our results suggest that pollinator-mediated selection in food-deceptive orchids can change in strength and in direction over time. In perennial plants, such as orchids, different selection differentials in the same populations in different flowering seasons can contribute to the maintenance of phenotypic variation often reported in deceptive orchids. 
1 Fluctuating selection across years and phenotypic variation in food-

2

3

\section{deceptive orchids}

1 Department of Biology, University of Naples Federico II, Naples, Italy

2 UMR Peuplements Végétaux et Bioagresseurs en Milieu Tropical, Université de la Réunion, Pôle de Protection des Plantes, Saint Pierre, La Réunion, France

${ }^{3}$ Department of Botany and Biodiversity Research, University of Vienna, Vienna, Austria

Correspondence

G. Scopece, Department of Biology, University of Naples Federico II, via Cinthia, I80126, Naples, Italy. Tel.: +39081679186; E-mail: giovanni.scopece@unina.it 
Nectarless flowers that deceive pollinators offer an opportunity to study asymmetric plant-insect interactions. Orchids are a widely used model for studying these interactions because they encompass several thousand species adopting deceptive pollination systems. High levels of intra-specific phenotypic variation have been reported in deceptive orchids, suggesting a reduced consistency of pollinator-mediated selection on their floral traits. Nevertheless, several studies report on widespread directional selection mediated by pollinators even in these deceptive orchids. In this study we test the hypothesis that the observed selection can fluctuate across years in strength and direction thus likely contributing to the phenotypic variability of this orchid group.

31 We performed a three-year study estimating selection differentials and selection gradients for nine phenotypic traits involved in insect attraction in two Mediterranean orchid species, namely Orchis mascula and O. pauciflora, both relying on a welldescribed food-deceptive pollination strategy.

We found weak directional selection and marginally significant selection gradients in the two investigated species with significant intra-specific differences in selection differentials across years.

Our data do not link this variation with a specific environmental cause, but our results suggest that pollinator-mediated selection in food-deceptive orchids can change in strength and in direction over time. In perennial plants, such as orchids, different selection differentials in the same populations in different flowering seasons can 
42 contribute to the maintenance of phenotypic variation often reported in deceptive 43 orchids. 
Pollinator-mediated selection is one of the main processes driving the evolution of floral traits in entomophilous pollen-limited plant species (Fenster et al., 2004). The typical form of entomophilous pollination is based on a reciprocal advantage: the flower offers a reward (typically pollen or nectar) to the pollinator, which transports the pollen to conspecific individuals ensuring reproduction. However, pollinators are a priori to visitation, able to directly assess the amount of nectar reward contained in the flowers and thus depend on the information provided by advertising floral traits (Benitez-Vieyra et al., 2010). Therefore, nectar-producing plants have an advantage in being easily recognisable by pollinators so that once a rewarding flower type is discovered, pollinators usually concentrate on a single species (flower constancy; Waser, 1986). In these plant-pollinator relationships, plants are continuously exposed to the choice of pollinators, which imposes a selection on flower traits (Schiestl \& Johnson, 2013). Pollinator-mediated selection is thus considered the main factor shaping changes in phenotypic floral trait distributions (Fenster et al., 2004). Accordingly, the development of easily applicable methods to estimate selection differentials in natural populations (Lande \& Arnold, 1983) resulted in the common discovery of directional selection on floral traits in many plant systems (Kingsolver et al., 2001; Hereford et al., 2004). Flower constancy is an important prerequisite for the establishment of strong selection associate with a reward, they favour individuals that are similar, and potentially shape the displacement of the phenotypic distribution of floral traits via the elimination of abnormal phenotypes that are not preferred by the pollinators (Waser, 1986). However, 
70 plant-pollinator interactions can be more intricate, and patterns of pollinator-mediated

71 selection may differ in the case of temporarily or spatially asymmetrical and non-

72 constant relationships.

73 Orchids are widely used as a model to study asymmetric plant-insect interactions because they include many species with nectarless flowers that deceive their pollinators (Ackerman, 1986; Schiestl, 2005; Jersàkovà et al., 2006). Among orchid deceptive pollination strategies, the most common is based on a generalised mimicry of floral traits that pollinators associate with the presence of nectar (generalised food-deception, Dafni, 1984). In these deceptively pollinated species, plant-pollinator interactions do not follow flower constancy behaviour because many species of insects learn to avoid deceptive flowers after a few rewardless visits (Gumbert, 2000; Smithson \& Gigord, 2003). This pollinator behaviour can result in disruptive selection leading to high phenotypic variability or, alternatively, to a relaxed selection on floral traits (Juillet \& Scopece, 2010) of deceptive orchids. This is also suggested by the high intra-specific phenotypic variability in flower traits that has been observed in this plant group, including colour (Nilsson, 1980), shape and size (Ackerman \& Galarza-Pérez, 1991), and fragrance (Moya \& Ackerman, 1993; Salzmann et al., 2007). In a survey, Ackerman et al. (2011) confirmed that such variation is more common in deceptive compared to nectar-rewarding species, thus suggesting that the maintenance of a high phenotypic variability may be linked with the adoption of a deceptive pollination system (see also Salzmann et al., 2007).

Factors maintaining high levels of phenotypic variation in deceptive systems have been

92 investigated in several studies (see Juillet \& Scopece 2010 and references therein), 
93 particularly after Heinrich's (1975) proposal that phenotypic variability decreases

94 pollinator avoidance learning, thereby increasing orchid reproductive success. This hypothesis has also been recently suggested by Stejskal et al. (2015) to explain variation in the labellum patterns of a sexually-deceptive orchid. However, Juillet and Scopece (2010) showed that all attempts to identify a reproductive advantage linked with phenotypic variation in food-deceptive species were non-significant or indicated a lower reproductive success thus underlining the need of more studies to support or discard this hypothesis. Other potential causes that could account for high phenotypic variation in deceptive species are negative frequency dependent selection (e.g. Gigord

et al., 2001) or genetic drift (Knapp \& Rice, 1998; Tremblay et al., 2005; Holderegger et al., 2006; Lawton-Rauh, 2008). However, negative frequency dependent selection was contradicted by several studies that excluded a reproductive advantage of the rarer phenotype (Juillet \& Scopece, 2010), both in species with discrete phenotypic polymorphism (Ackerman \& Carromero, 2005; Pellegrino et al., 2005; Smithson et al., 2007; Tremblay \& Ackerman, 2007) and in species with continuous phenotypic variation (Salzmann et al., 2007; Aragòn \& Ackerman, 2004). Nevertheless, despite high levels of phenotypic variation, there is increasing evidence for directional selection on floral traits in food-deceptive orchids. For example,

111 pollination success was found to be correlated with plant height in Cypripedium acaule 112 (O'Connell \& Johnston, 1998), to the number of flowers in Anacamptis morio (Johnson 113 \& Nilsson, 1999), to spur length in the Disa draconis species complex (Johnson \&

114 Steiner, 1997) and in hybrid zones between Anacamptis morio and A. Iongicornu (Zitari 115 et al., 2012), to flowering time in some deceptive orchids (Sabat \& Ackerman, 1996; 
116 O'Connell \& Johnston, 1998; Sun et al., 2009; but see Sletvold et al. 2010), to plant

117 height, flower number and spur length in Dactylorhiza lapponica (Sletvold et al., 2010)

118 and to flower brightness and contrast in Anacamptis morio (Sletvold et al., 2016). This

119 evidence is unexpected, considering the high levels of phenotypic variation seen in

120 deceptive orchids and suggests that, even in this plant group, directional selection

121 mediated by pollinators may be widespread and strong (but see Cintròn Berdecia \&

122 Tremblay, 2003). However, these studies were performed in single flowering seasons

123 and disregarded the fact that across years natural selection can vary in both the

124 strength and direction (Darwin, 1859; Grant \& Grant, 1989; Benitez-Vieyra et al., 2012;

125 Sletvold \& Ågren, 2014). Temporal variation in patterns of natural selection has been

126 often documented in plants (Harder \& Johnson, 2009) and has been linked to variation

127 in the pollinator community (Conner et al., 2003), to the presence of herbivores

128 (Sandring et al., 2007), and to abiotic factors (Maad, 2000; Caruso et al., 2003; Cintròn

129 Berdecia \& Tremblay, 2003; Maad \& Alexandersson, 2004). Despite this evidence,

130 however, the incidence of seasonal variation on selection patterns in deceptive orchid

131 species has been rarely investigated (Tremblay et al., 2010).

132 By estimating the covariance of pollination success with nine different phenotypic traits,

133 we estimated selection differentials and gradients in two Mediterranean food-deceptive

134 orchid species, Orchis mascula and Orchis pauciflora. In particular, we estimated the

135 strength and direction of natural selection over three consecutive years in a sympatric

136 population of these two species with the aim of specifically understanding whether, in

137 the same population, pollinator-mediated selection shows a concordant pattern over

138 different years. We used two orchid species with similar flower morphology and a 
139 common set of pollinators (Van der Cingel, 1995; Cozzolino et al., 2006; Nilsson, 2008;

140 Valterovà et al., 2007) as replicates to increase the power of our conclusions for

141 Mediterranean food-deceptive orchids.

MATERIALS AND METHODS

\section{Study System}

Orchis mascula and $O$. pauciflora are closely related species in the orchid subtribe

Orchidinae (Aceto et al., 1999). O. mascula is a widespread European species, ranging

from Sweden to the northern borders of the Mediterranean basin (Sundermann, 1980).

It is typically found in sunny meadows or calcareous grasslands up to $2400 \mathrm{~m}$ in

altitude. O. pauciflora is generally found on poorer calcareous soils in the south-eastern

and central part of the Mediterranean basin, up to $1500 \mathrm{~m}$ in altitude.

The two species are self compatible but non autogamous and rely on generalised fooddeception for pollinator attraction (Van der Cingel, 1995). Hymenopterans are the most common pollinators of these two species (specifically Bombus sp., but also species of the genus Psithyrus, Eucera, Andrena, Osmia, Anthophora), and reproductive success is severely pollen-limited (e.g., Cozzolino et al., 2006). Clonal propagation is extremely rare in both species.

157 Our study was performed during Spring of 2002, 2003 and 2004 in sympatric natural populations of O. mascula and O. pauciflora located in the Cilento and Vallo di Diano National Park (Southern Italy). For each species, and in each year, plants were randomly selected in subgroups in an area of approximately $4 \mathrm{~km}^{2}$ where distribution was nearly continuous. We labelled and measured a total of 1188 individuals (492 0. 
162 mascula and 696 O. pauciflora; for details see Supplementary information). Due to the

163 big dimensions of the populations the likelihood of resampling the same individuals

164 across years was very low.

165

166

\section{Morphological measurement and data collection}

167

To investigate pollinator-mediated selection, we measured nine morphological traits that are potentially important for pollinator visual attraction. Morphological trait measurements were obtained on the same day and at a time when all the examined plants were at peak flowering, i.e. when all flowers of the inflorescence were open. For each individual that was sampled in this study, we recorded two "inflorescence size" variables: 1) flower number and 2) plant height (from ground to uppermost flower, to the nearest $\mathrm{cm}$ ). We

173 measured also three "flower size" variables: 3 ) labellum width (distance between the edges of the two lateral lobes, to the nearest $0.1 \mathrm{~mm}$ ), 4) labellum length (distance between the labellum tip and spur mouth, to the nearest $0.1 \mathrm{~mm}$ ) and 5) spur length 176 (distance between the spur mouth and the spur tip, to the nearest $0.1 \mathrm{~mm}$ ). To obtain

177 these measurements, sampled flowers were dissected and floral elements were placed between two transparent plastic film sheets (supplementary figure 1). These sheets were subsequently scanned to obtain digital images in a 300 dpi TIFF format with a coordinate millimetre paper on the back for reference; measures of floral traits were later obtained using ImageJ 1.33 software (Rasband, National Institutes of Health, USA). Finally, as previously described by Bradshaw et al. (1998), we measured the pigment content in flower elements using a spectrophotometric method. Anthocyanin concentration (purple pigment) was estimated from tepals and labellum, extracting the pigment with $0.5-\mathrm{ml}$ methanol/0.1\% HCl, and determining the absorbance at $510 \mathrm{~nm}$; carotenoid 
186 concentration (yellow pigment) was estimated similarly, using methylene chloride for 187 pigment extraction and measuring absorbance at $450 \mathrm{~nm}$. We thus estimated four "flower

188

189

190

191

192

193

194

195

196

197

198

199

200

201

202

203

204

205

206

207

208

colour" variables: 6) anthocyanin content in tepals, 7) anthocyanin content in labellum, 8)

carotenoid content in tepals and 9) carotenoid content in labellum.

We estimated pollen limitation $(P L)$ as 1 - (mean female fitness of open-pollinated plants/mean female fitness of hand pollinated plants), ranging from 0 to 1 . Female fitness of open pollinated plants was recorded on the same individuals used for traits measurements and was defined as the number of fruits produced by an individual relative to its number of flowers; female fitness of hand pollinated plants was calculated similarly based on literature data reporting results of crossing experiments conducted in the same populations (Scopece et al., 2007).

(1)

8

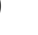

\section{Data analysis}

All analyses were performed independently for the two species and were conducted using R 2.1.1 software (R Development Core Team 2005). To explore the relationship among floral traits, we performed Spearman's rank correlation. We examined significant differences in floral traits across years using Kruskal-Wallis tests of difference and posthoc pairwise comparisons using Nemenyi test. To explore the level of variation of floral traits, for both investigated species, we calculated a coefficient of variation (CV) as the ratio between Standard deviation and mean. CVs were calculated for each trait in the three investigated years and then averaged to obtain a value for each of the two 
species.

210 We estimated selection differentials (Lande \& Arnold, 1983; Brodie et al., 1995) as the

211 covariance between relative reproductive success and each morphological trait. Plant

212 reproductive success was measured at the end of the flowering period as fruit set, i.e.,

213 number of fruit / number of flower, ranging from 0 to 1 . The relative reproductive

214 success of an individual was defined as its fruit set divided by the mean population fruit

215 set. Morphological traits were scaled by population mean and standard deviation (z-

216 scores, Lynch \& Walsh, 1998). To compare selection differentials over different years,

217 we computed bootstrap bias-corrected confidence intervals (Cls: Maad \&

218 Alexandersson, 2004). Non-overlapping Cls indicated significantly different selection

219 differentials, Cls including 0 were deemed be non-significant.

220 To estimate selection gradients, following Lande \& Arnold (1983), we performed

221 multiple single linear regressions using relative fitness as dependent variable and

222 standardized traits (z-scores) as predictors. This method was used to produce a simple

223 comparison among traits and years, In alternative to a detailed modelling of selection

224 gradients ( as performed in Schluter, 1988; Tremblay, 2001) here we used scaled traits

225 (z-scores) to satisfy as best as possible the mathematical assumptions underlying

226 regression equations (i.e. normality).

227

228

\section{RESULTS}

229

All floral traits were moderately and positively correlated with the exception of

230 carotenoid content in tepals and labellum, which were negatively correlated with other 
231 phenotypic traits (Table 1). In both species, several floral traits showed significant

232 differences across different years (Fig. 1, Fig. 2).

233 In both investigated species, CVs were extremely high for all floral traits indicating a

234 high variability of floral traits with a slight variation across years. Average CV was 0.35

235 in O. mascula and 0.42 in O. pauciflora (See Supporting information).

236 Data from Scopece et al. (2007) showed that, in both species, the ratio between hand237 pollinated flowers and fruits developed was very high ( 1 for 0 . mascula and 0.92 for $O$. 238 pauciflora), in contrast with fruit formation in open-pollinated individuals, which was low 239 (0.11 in O. mascula and 0.10 in 0 . pauciflora). Thus, both species were severely pollen240 limited (PL for O. mascula $=0.89 ; \mathrm{PL}$ for O. pauciflora $=0.87$ ).

241 All of the investigated floral traits in both species showed some amount of selection 242 across years (Fig. 1, Fig. 2). A comparison of the selection differentials in three 243 consecutive years revealed significant differences for 7 traits in both O. mascula (Fig. 1) 244 and O. pauciflora (Fig. 2). Specifically, in O. mascula, selection differentials were 245 significantly different for 6 out of 9 traits between 2002 and 2003, 3 out of 9 between 2462003 and 2004, and 3 out of 9 between 2002 and 2004 (Fig. 1). In O. pauciflora, 247 selection differentials were significantly different for 2 out of 9 traits between 2002 and 248 2003, 6 out of 9 between 2003 and 2004, and 2 out of 9 between 2002 and 2004 (Fig. 249 2).

250 Across the three years, the selection differential patterns were generally consistent with

251 floral trait variation (i.e., decrease when floral traits increase). In O. mascula, the

252 patterns were consistent in 7 out of 9 traits. In O. pauciflora, the patterns were 253 consistent in 6 out of 9 traits. 
254 We also found changes in the direction of selection (i.e., sign of selection differential) in 2553 out of 9 floral traits in O. mascula (Fig. 1) and in 3 out of 9 floral traits in O. pauciflora 256 (Fig. 2). Selection gradients for each investigated population are reported in Table 2. 257 Results suggest only few marginally significant values indicating weak direct selection 258 on some of the floral traits.

259

260 
262 The quantification and interpretation of the direction, strength and causes of natural

263

264 selection have been at the centre of scientific debate since the formulation of Darwin's theory (Darwin, 1859). Among the main aims of studies on selection is the capture of snapshots and milestones in the process of phenotypic trait evolution mediated by natural selection. Thus far, many studies have shown that some of the characters appear to have some advantage over others which suggest that phenotypic selection can be monitored in different animal or plant organisms (Kingsolver et al., 2001; Hereford et al., 2004), generating the idea that directional selection is widespread in natural populations. This idea is confirmed by the general stability of phenotypic traits observed in rewarding plant species, but it apparently conflicts with the elevated variation observed in deceptive species (Ackerman et al., 2011). In this study, we estimated selection differentials and gradients for nine floral traits in two Mediterranean food-deceptive orchid species, Orchis mascula and O. pauciflora over three consecutive years. Overall, we found some degree of phenotypic selection on all of the investigated traits but a strong variation in direction and intensity over different years (Fig. 1, Fig. 2). As expected in deceptive orchids (Tremblay et al., 2005), we found that the two investigated species showed high levels of pollinator limitation. Although pollen limitation is not predictive of pollinator-mediated selection, in severely pollen-limited species the strength of selection is mainly due to the action of pollinators (Sletvold et al., 2010; Sletvold \& Agren, 2014). Despite increasing evidence showing pollinatormediated selection in Mediterranean food-deceptive orchids (Johnson \& Steiner, 1997; O'Connell \& Johnston, 1998; Johnson \& Nilsson, 1999; Sun et al., 2009; Sletvold et al., 
284 2010; Zitari et al., 2012; Sletvold et al., 2016), our results showed a weak and variable

285 selection on floral traits when analysed over different, consecutive seasons suggesting

286 the absence of constant directional selection on these species. As already reported in

287 Tremblay et al. (2010) and in Ackerman \& Galarza-Pérez (1991), the inconsistency in

288 strength and direction can potentially be responsible for the elevated phenotypic

289 variation that we directly assessed in the investigated species through the calculation of

290 coefficients of variation for morphological traits that were on average higher than those

291 reported in previous literature surveys on deceptive orchid species (i.e. 0.35 in O.

292 mascula and 0.42 in O. pauciflora versus an average of $15.2 \%$ in the deceptive species

293 and of $11.1 \%$ for the rewarding species reported in Ackerman et al., 2011). Indeed, we

294 found that selection differentials significantly varied at least once in direction or strength

295 in 7 out of 9 traits in both O. mascula and O. pauciflora over different years (Fig. 1, Fig.

296 2) with a total of 12 changes out of 27 comparisons in O. mascula (Fig. 1) and 10

297 changes out of 27 in O. pauciflora (Fig. 2). In both investigated species, most of the

298 studied floral traits were positively correlated (Table 1), which could in principle mask

299 the action of natural selection in the selection differential analysis (Lande \& Arnold,

300 1983). However, our analysis of selection gradient showed only a few marginally

301 significant results, thus confirming the weak selection observed in selection differentials

302 (see Table 2).

303 Floral traits were not constant over different years and most of these traits showed

304 significant differences in different reproductive seasons (Fig. 1, Fig. 2). In several cases, 305 selection differentials were consistent with phenotypic trait variation; e.g., in O. mascula, 306 plant height was under stronger selection when plants were less tall (Fig. 1), thus 
307 suggesting a weak directional selection over the years. However, for other traits,

308 selection differentials were inconsistent with this phenotypic variation (Fig. 1, Fig. 2),

309 which suggests that fluctuations of natural selection for these traits are not an artefact

310 but rather reflect the activities of different selective agents in different years.

311 Significant differences among floral traits in different years, within the same population,

312 may be explained as a consequence of phenotypic plasticity. Indeed, in a variable

313 environment, a single generalist genotype can potentially express a wide range of

314 random phenotypes or show different responses to environmental cues via phenotypic

315 plasticity (Kawecki \& Ebert, 2004; Hill \& Mulder, 2010; Morales et al., 2010). In our

316 study, this can be accentuated by the extreme climatic conditions of the 2003 heat wave

317 (Beniston, 2004).

318 Interestingly, in 2003, measurements showed a quantitative reduction of most floral

319 traits (Fig. 1, Fig. 2). However, despite the contribution of plasticity on the phenotypic

320 expression of the investigated floral traits, their heritability was verified by a comparison

321 of phenotypic expression of traits in hybrid zones (Scopece et al., unpublished).

322 Fluctuating selection has been proposed to be common in natural populations

323 (Siepielski et al., 2009; Kimball et al., 2012), but its potential role is still debated

324 particularly due to the dearth of extensive multi-year studies (Tremblay et al., 2010). In

325 our study, with a multi-year dataset, we showed that the change in the direction and

326 intensity of selection on the same floral traits could determine a continuous but

327 fluctuating pressure that favours different individuals in different years. Within the same

328 population, this can potentially result in the maintenance of variable phenotypes.

329 Indeed, although changes in selective pressures in annual plant species may generate 
330 a displacement of phenotypic traits, in perennial long-lived plants such as orchids, the

331 individual's reproductive success is the result of its performance during its lifetime and

332 thus only a selection that is constant over time can generate displacement or

333 stabilisation of the distribution of phenotypic traits. In contrast, fluctuating selection is

334 more likely to explain the phenotypic variation observed in the natural populations of

335 deceptive orchids.

336 The main source of this fluctuating selection is most likely the action of pollinators. In

337 the nectar-rewarding orchid Gymnadenia conopsea, spatio-temporal variation in

338 interactions with pollinators contributes to among-years and among-populations

339 variation in selection on floral traits but that several traits are also likely to be subject to

340 different selective agents (Sletvold \& Ågren, 2010; Chapurlat et al., 2015). In our study,

341 we focused on severely pollen-limited food-deceptive species in which pollinators are

342 likely to be the main selective agents (Tremblay et al., 2005; Sletvold et al., 2010;

343 Sletvold \& Ågren, 2014). Furthermore, direct estimation based on the comparison of

344 reproductive performance between open-pollinated and hand-pollinated plants

345 confirmed elevated levels of pollinator limitation for the two investigated species (PL for

346 O. mascula $=0.89 ; \mathrm{PL}$ for $\mathrm{O}$. pauciflora $=0.87$. . Pollinator-mediated selection is a

347 complex process that can be affected by a high number of environmental variables. For

348 example, pollinators with different tongue lengths may exert different selection

349 pressures that positively select flowers with shorter or longer nectar spurs (Johnson \&

350 Steiner, 1997). However, pollinator community varies over the flowering season and in

351 different years depending on climatic differences that can alter both the phenology of

352 plants and emergence of pollinators (Fisogni et al., 2016). Moreover, for similar 
353 reasons, the surrounding plant community may change in different years, thereby

354 influencing local pollinator preference and abundance (Herrera, 1988; Schemske \&

355 Horvitz, 1989). The change in pollinators or surrounding plant community composition is

356 particularly crucial for generalist deceptive species such as O. mascula and $O$.

357 pauciflora, which attract a wide range of available pollinator species, and is the most

358 likely source of the observed changes in selection differentials. Changes in pollinator-

359 mediated selection have been widely documented in plant species, including orchids,

360 and have been attributed to many environmental variables (e.g., Caruso et al., 2003;

361 Conner et al., 2003; Gòmez et al., 2003; Toräng et al., 2008; Sletvold \& Ågren, 2010).

362 However, identifying the source of variation in selection differentials can only be

363 achieved via detailed community ecological studies at the local scale. For instance,

364 similar attempts have previously shown that vegetation height affects the strength of

365 pollinator-mediated selection in the food-deceptive orchid Dactyloriza lapponica

366 (Sletvold et al., 2013), thus suggesting that variation in selection also occurs within the

367 same reproductive season at small geographic scales.

368 A different mechanism that have been advocated to explain the maintenance of high

369 phenotypic variation in deceptive species is the genetic drift. In this scenario, repeated

370 founder events and or small effective population sizes would generate phenotypic

371 variation (Gentry \& Dodson, 1987; Zimmerman \& Aide, 1989; Tremblay \& Ackerman,

372 2001). In support of this scenario is the observation that deceptive orchids typically have

373 lower fruit set and higher fruiting failure than nectar-rewarding species (Neiland \&

374 Wilcock, 1998; Tremblay et al., 2005) thus resulting in a reduced effective population

375 size that would consequently increase the chances of genetic drift. In this context, if 
376 pollinator-mediated selection is weak, then genetic drift could account for high variation.

377 Fluctuating pollinator-mediated selection and genetic drift can thus both contribute to

378 the observed pattern of high phenotypic variation in deceptive orchids and the relative

379 importance of the two processes should be object of future researches.

380 Future research avenues should also address the basis of the elevated phenotypic

381 variation of food-deceptive species and confirm whether similar variation occurs even at

382 a fine geographic scale. Such studies should include fine scale community ecological

383 investigations, as for instance temporal and local variation in pollinator community, that

384 aim to disentangle the factors affecting variation. Simultaneously, it would also be

385 important to conduct more studies on nectar-rewarding orchids to test for the opposite

386 pattern, i.e., lower variability of selection pressures in space and time.

\section{ACKNOWLEDGEMENTS}

Authors thank A.M. Nardella and S. Impagliazzo for help with field-work and the Cilento and Vallo di Diano National Park for permissions and logistic support. The authors also thank Elodie Chapurlat, RL Tremblay and JD Ackerman that revised a previous version of this manuscript.

\section{REFERENCES}

Aceto S, Caputo P, Cozzolino S, Gaudio L, Moretti A. 1999. Phylogeny and evolution of Orchis and allied genera based on ITS DNA variation: morphological gaps and molecular continuity. Molecular Phylogenetics and Evolution 13:67-76. 
399

400

401

402

403

404

405

406

407

408

409

410

411

412

413

414

415

416

417

418

419

Ackerman JD. 1986. Mechanisms and evolution of food-deceptive pollination systems in orchids. Lindleyana 1:108-113.

Ackerman JD, Carromero W. 2005. Is reproductive success related to color polymorphism in a deception pollinated terrestrial orchid? Caribbean Journal of Science 41:234-242.

Ackerman JD, Cuevas AA, Hof D. 2011. Are deception-pollinated species more variable than those offering a reward? Plant Systematics and Evolution 293:91-99.

Ackerman JD, Galarza-Pérez M. 1991. Patterns and maintenance of extraordinary variation in the Caribbean orchid, Tolumnia (Oncidium) variegata. Systematics Botany 16:182-194.

Aragón S, Ackerman JD. 2004. Does flower colour variation matter in deception pollinated Psychilis monensis (Orchidaceae)? Oecologia 138:332-338.

Beniston M. 2004. The 2003 heat wave in Europe: A shape of things to come? An analysis based on Swiss climatological data and model simulations. Geophysical Research Letters 31:1-4.

Benitez-Vieyra S, Ordano M, Fornoni J, Boege K, Domínguez CA. 2010. Selection on signal-reward correlation: limits and opportunities to the evolution of deceit in Turnera ulmifolia L. Journal of Evolutionary Biology 23:2760-2767.

Benitez-Vieyra S, Glinos E, Medina AM, Cocucci AA. 2012. Temporal variation in the selection on floral traits in Cyclopogon elatus (Orchidaceae). Evolutionary Ecology 26:1451-1468. 
420 Bradshaw HD, Otto KG, Frewen BE, McKay JK, Schemske DW. 1998. Quantitative

421 trait loci affecting differences in floral morphology between two species of

422 monkeyflower (Mimulus). Genetics 149:367-382.

423 Brodie ED, Moore AJ, Janzen FJ. 1995. Visualizing and quantifying natural selection.

424 Trends in Ecology and Evolution 10:313-318.

425 Caruso CM, Peterson SB, Ridley CE. 2003. Natural selection on floral traits of Lobelia 426 (Lobeliaceae): spatial and temporal variation. American Journal of Botany 90:13334271340.

428 Chapurlat E, Ågren J, Sletvold N. 2015. Spatial variation in pollinator-mediated 429 selection on phenology, floral display and spur length in the orchid Gymnadenia 430 conopsea. New Phytologist 208:1264-1275.

431 Cintrón Berdecía ST, Tremblay RL. 2003. Phenotypic selection in Lepanthes rupestris 432 Stimson. Lankersteriana 7:70-72.

433 Conner JK, Rice AM, Stewart C, Morgan MT. 2003. Patterns and mechanisms of 434 selection on a family-diagnostic trait: evidence from experimental manipulation and 435 lifetime fitness selection gradients. Evolution 57:480-486. and conservation of Mediterranean orchids: should we protect the orchid hybrids or the orchid hybrid zones? Biological Conservation 129:14-23.

Dafni A. 1984. Mimicry and deception in pollination. Annual Review of Ecology and Systematics 15:259-278.

441 Darwin CR. 1859. On the origin of species by means of natural selection, or the 442 preservation of favoured races in the struggle for life. London: John Murray. 
443 Fenster CB, Armbruster WS, Wilson P, Dudash MR, Thomson JD. 2004. Pollination

444 syndromes and floral specialization. Annual Review of Ecology and Systematics

$445 \quad 35: 375-403$.

446 Fisogni A, Rossi M, Sgolastra F, Bortolotti L, Bogo G, de Manincor N, Quaranta M,

447 Galloni M. 2016. Seasonal and annual variations in the pollination efficiency of a

448 pollinator community of Dictamus albus L. Plant Biology 18:445-454.

449 Gentry AL, Dodson CH. 1987. Diversity and biogeography of neotropical vascular

450 epiphytes. Annals of the Missouri Botanical Garden 74:205-233.

451 Gigord LDB, Macnair MR, Smithson A. 2001. Negative frequency-dependent selection

452 maintains a dramatic flower color polymorphism in the rewardless orchid Dactylorhiza

453 sambucina (L.) Soò. Proceedings of the National Academy of Sciences USA 98:6253-

$454 \quad 6255$.

455 Gòmez JM. 2003. Herbivory reduces the strength of pollinator-mediated selection in the

456 Mediterranean herb Erysimum mediohispanicum: consequences for plant

457 specialization. American Naturalist 162:242-256.

458 Grant BR, Grant PR. 1989. Natural selection in a population of Darwin's finches.

459 American Naturalist 133:377-393.

460 Gumbert A. 2000. Color choices by bumble bees (Bombus terrestris): innate

461 preferences and generalization after learning. Behavioral Ecology and Sociobiology

$462 \quad 48: 36-43$.

463 Harder LD, Johnson SD. 2009. Darwin's beautiful contrivances: evolutionary and

464 functional evidence for floral adaptation. New Phytologist 183:530-545.

465 Heinrich B. 1975. Bee flowers: a hypothesis on flower variety and blooming times. 
Evolution 29:325-334.

467 Hereford J, Hansen TF, Houle D. 2004. Comparing strengths of directional selection:

468 how strong is strong? Evolution 58:2133-2143.

469 Herrera CM. 1988. Variation in mutualisms: the spatio-temporal mosaic of a pollinator

470 assemblage. Biological Journal of the Linnean Society 35:95-125.

471 Hill WG, Mulder HA. 2010. Genetic analysis of environmental variation. Genetics

$472 \quad$ Research 92:381-395.

473 Holderegger R, Kamm U, Gugerli F. 2006. Adaptive vs. neutral genetic diversity:

474 implications for landscape genetics. Landscape Ecology 21:797- 807.

475 Jersàkovà J, Johnson SD, Kindlman P. 2006. Mechanisms and evolution of deceptive 476 pollination in orchids. Biological Reviews 81:219-235.

477 Johnson SD, Steiner KE. 1997. Long-tongued fly pollination and evolution of floral spur 478 length in the Disa draconis complex (Orchidaceae). Evolution 51:45-53.

479 Johnson SD, Nilsson LA. 1999. Pollen carryover, geitonogamy, and the evolution of 480 deceptive pollination system in orchids. Ecology 80:2607-2619.

481 Juillet N, Scopece G. 2010. Does floral trait variability enhance reproductive success in 482 deceptive orchids? Perspectives in Plant Ecology Evolution and Systematics 12:317$483 \quad 322$.

484 Kawecki TJ, Ebert D. 2004. Conceptual issues in local adaptation. Ecology Letters 7, $485 \quad 1225-1241$.

486 Kimball S, Gremer JR, Angert AL, Huxman TE, Venable DL. 2012. Fitness and 487 physiology in a variable environment. Oecologia 169:319-329.

488 Kingsolver JG, Hoekstra HE, Hoekstra JM, Berrigan D, Vignieri SN, Hill CE, Hoang 
489

490

491

492

493

494

495

496

497

498

499

500

501

502

503

504

505

506

507

508

509

510

511

A, Gibert P, Beerli P. 2001. The strength of phenotypic selection in natural populations. American Naturalist 157:245-261.

Knapp EE, Rice KJ. 1998. Comparison of isozymes and quantitative traits for evaluating patterns of genetic variation in purple needlegrass (Nassella pulchra). Conservation Biology, 12:1031-1041.

Lande R, Arnold SJ. 1983. The measurement of selection on correlated characters. Evolution 37:1210-1226.

Lawton-Rauh A. 2008. Demographic processes shaping genetic variation. Current Opinion in Plant Biology 11:103-109.

Lynch M, Walsh B. 1998. Genetics and Analysis of Quantitative Traits. Sunderland: Sinauer Associate.

Maad J. 2000. Phenotypic selection in hawkmoth-pollinated Platanthera bifolia: targets and fitness surfaces. Evolution 54:112-123.

Maad J, Alexandersson R. 2004. Variable selection in Platanthera bifolia (Orchidaceae): phenotypic selection differed between sex functions in a drought year. Journal of Evolutionary Biology 17:642-650.

Morales M, Ackerman JD, Tremblay RL. 2010. Morphological flexibility across an environmental gradient in the epiphytic orchid, Tolumnia variegata: complicating patterns of fitness. Botanical Journal of the Linnean Society 163:431-446.

Moya S, Ackerman JD. 1993. Variation in the floral fragrance of Epidendrum ciliare (Orchidaceae). Nordic Journal of Botany 13:41-47.

Neiland MR, Wilcock CC. 1998. Fruit set, nectar reward, and rarity in the Orchidaceae. American Journal of Botany 85:1657-1671. 
512 Nilsson LA. 1980. The pollination ecology of Dactylorhiza sambucina (Orchidaceae).

513 Botaniska Notiser 133, 367-385.

514 Nilsson LA. 2008. Anthecology of Orchis mascula (Orchidaceae). Nordic Journal of

515 Botany 3:157-179.

516 O'Connell LM, Johnston MO. 1998. Male and female pollination success in a deceptive

517 orchid: a selection study. Ecology 79:1246-1260.

518 Pellegrino G, Caimi D, Noce ME, Musacchio A. 2005. Effects of local density and

519 flower colour polymorphism on pollination and reproduction in the rewardless orchid

520 Dactylorhiza sambucina (L.) Soò. Plant Systematics and Evolution 251:119-129.

521 Sabat A, Ackerman D. 1996. Fruit set in a deceptive orchid: the effect of flowering

522 phenology, display size, and local floral abundance. American Journal of Botany

$523 \quad 83: 1181-1186$.

524 Salzmann CC, Nardella AM, Cozzolino S, Schiestl FP. 2007. Variability in floral scent

525 in rewarding and deceptive orchids: the signature of pollinator-imposed selection?

526 Annals of Botany 100:757-765.

527 Sandring S, Riihimäki MA, Savolainen O, Ágren J. 2007. Selection on flowering time

528 and floral display in an alpine and a lowland population of Arabidopsis lyrata. Journal

529 of Evolutionary Biology 20:558-567.

530 Schemske DW, Horvitz CC. 1989. Temporal variation in selection on a floral character.

531 Evolution 43:461-465.

532 Schiestl FP. 2005. On the success of a swindle: pollination by deception in orchids. Naturwissenschaften 92:255-264.

534 Schiestl FP, Johnson SD. 2013. Pollinator-mediated evolution of floral signals. Trends 
535 in Ecology and Evolution 28:307-315.

536 Schluter D. 1988. Estimating the form of natural selection on a quantitative trait.

537 Evolution 42: 849-861.

538 Scopece G, Musacchio A, Widmer A, Cozzolino S. 2007. Patterns of reproductive 539 isolation in Mediterranean deceptive orchids. Evolution 61:2623-2642.

540 Siepielski AM, Di Battista JD, Carlson SM. 2009. It's about time: the temporal 541 dynamics of phenotypic selection in the wild. Ecology Letters 12:1261-1276.

542 Sletvold N, Grindeland JM, Agren J. 2010. Pollinator-mediated selection on floral traits 543 and flowering phenology in the deceptive orchid Dactylorhiza lapponica. New

544 Phytologist 188:385-392.

545 Sletvold N, Ågren J. 2010. Pollinator-mediated selection on floral display and spur 546 length in the orchid Gymnadenia conopsea. International Journal of Plant Sciences, $547 \quad$ 171:999-1009.

548 Sletvold N, Grindeland JM, Ågren J. 2013. Vegetation context influences the strength 549 and targets of pollinator-mediated selection in a deceptive orchid. Ecology 94:123655042.

551 Sletvold N, Ågren J. 2014. There is more to pollinator-mediated selection than pollen 552 limitation. Evolution 68:1907-1918.

553 Sletvold N, Trunschke J, Smit M, Verbeek J, Ågren J. 2016. Strong pollinator-

554 mediated selection for increased flower brightness and contrast in a deceptive orchid.

555 Evolution 70:716-724.

556 Smithson A, Gigord LDB. 2003. The evolution of empty flowers revisited. American $557 \quad$ Naturalist, 161:537-552. 
558 Stejskal K, Streinzer M, Dyer A, Paulus HF, Spaethe J 2015. Functional significance

559 of labellum pattern variation in a sexually deceptive orchid (Ophrys heldreichii):

560 Evidence of individual signature learning effects. Plos One 10:e0142971.

561 Sun H-Q, Cheng J, Zhang F-M, Luo, Y-B, Ge S. 2009. Reproductive success of non562 rewarding Cypripedium japonicum benefits from low spatial dispersion pattern and 563 asynchronous flowering. Annals of Botany 103:1227-1237.

564 Sundermann H. 1980. Europäische und mediterrane Orchideen. Hildesheim: Brücke 565 Verlag Kurt Schmersow.

566 Toräng P, Ehrlén J, Ågren J. 2008. Mutualists and antagonists mediate frequency567 dependent selection on floral display. Ecology 89:1564-1572.

568 Tremblay RL. 2011. Fitness landscapes in orchids: Parametric and non-parametric approaches. Lankesteriana 11(3): 355-362.

570 Tremblay RL, Ackerman JD. 2001. Gene flow and effective population size in

571 Lepanthes (Orchidaceae): a case for genetic drift. Biological Journal of the Linnean

572 Society $72: 47-62$.

573 Tremblay RL, Ackerman JD. 2007. Apparent neutrality of floral color in a tropical orchid:

574 spatial and temporal variation in reproductive success. Plant Species Biology 22:95575105.

576 Tremblay RL, Ackerman JD, Zimmerman JK, Calvo RN. 2005. Variation in sexual

577 reproduction in orchids and its evolutionary consequences: a spasmodic journey to 578 diversification. Biological Journal of the Linnean Society, 84:1-54. 
579 Tremblay RL, Ackerman JD, Pérez M-E. 2010. Riding across the selection landscape:

580 fitness consequences of annual variation in reproductive characteristics. Philosophical

581 Transactions of the Royal Society B 365: 491-498.

582 Valterovà I, Kunze J, Gumbert A, Luxovà A, Liblikas I, Kalinovà B, Borg-Karlson A-

B. 2007. Male bumble bee pheromonal components in the scent of deceit pollinated orchids; unrecognized pollinator cues? Arthropod-Plant Interactions 1:137-145.

Van Der Cingel NA. 1995. An atlas of orchids pollination-European orchids. Rotterdam, Netherlands: Balkema.

Waser NM. 1986. Flower constancy: definition, cause, and measurement. American Naturalist 127:593-603.

Zimmerman JK, Aide TM. 1989. Patterns of fruit production in a neotropical orchid: pollinator vs. resource limitation. American Journal of Botany 76:67-73.

Zitari A, Scopece G, Helal AN, Widmer A, Cozzolino S. 2012. Is floral divergence sufficient to maintain species boundaries upon secondary contact in Mediterranean food-deceptive orchids? Heredity 108:219-228.

Figure 1 Morphological traits (panels A) and selection differentials (panels B) in Orchis mascula. Different letters indicate significant differences.

Figure 2 Morphological traits (panels A) and selection differentials (panels B) in Orchis pauciflora. Different letters indicate significant differences. 


\section{Figure 1}

Morphological traits (white bars) and selection differentials (grey bars) in Orchis mascula.

A) Plant height, B) flower number, C) labellum width, D) labellum length, E) spur length, F) anthocyanin (tepals), G) anthocyanin (labellum), H) carotenoids (tepals), I) carotenoids (labellum). Different letters indicate significant differences. 

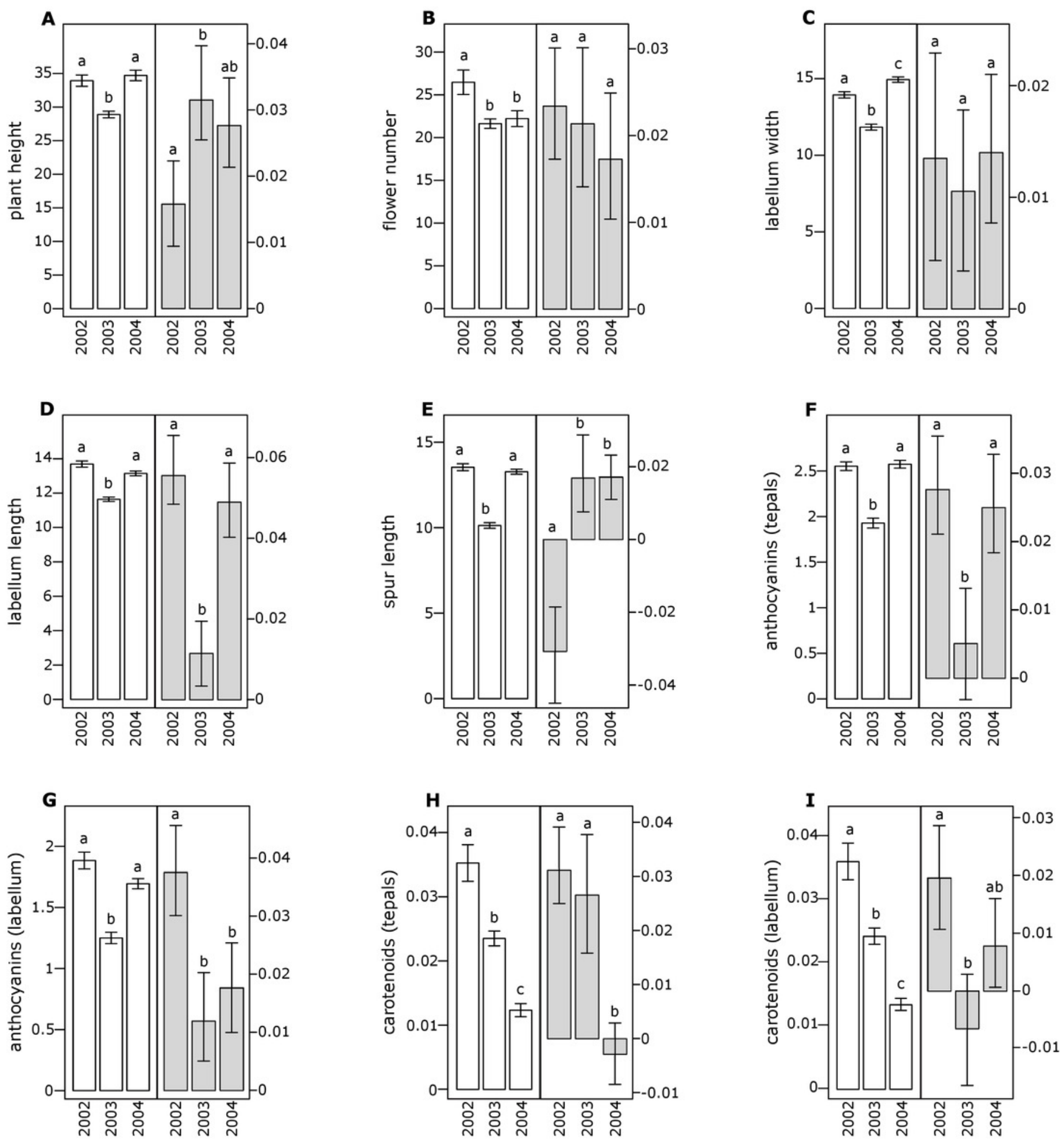
Figure 2

Morphological traits (white bars) and selection differentials(grey bars) in Orchis pauciflora.

A) Plant height, B) flower number, C) labellum width, D) labellum length, E) spur length, F) anthocyanin (tepals), G) anthocyanin (labellum), H) carotenoids (tepals), I) carotenoids (labellum). Different letters indicate significant differences. 

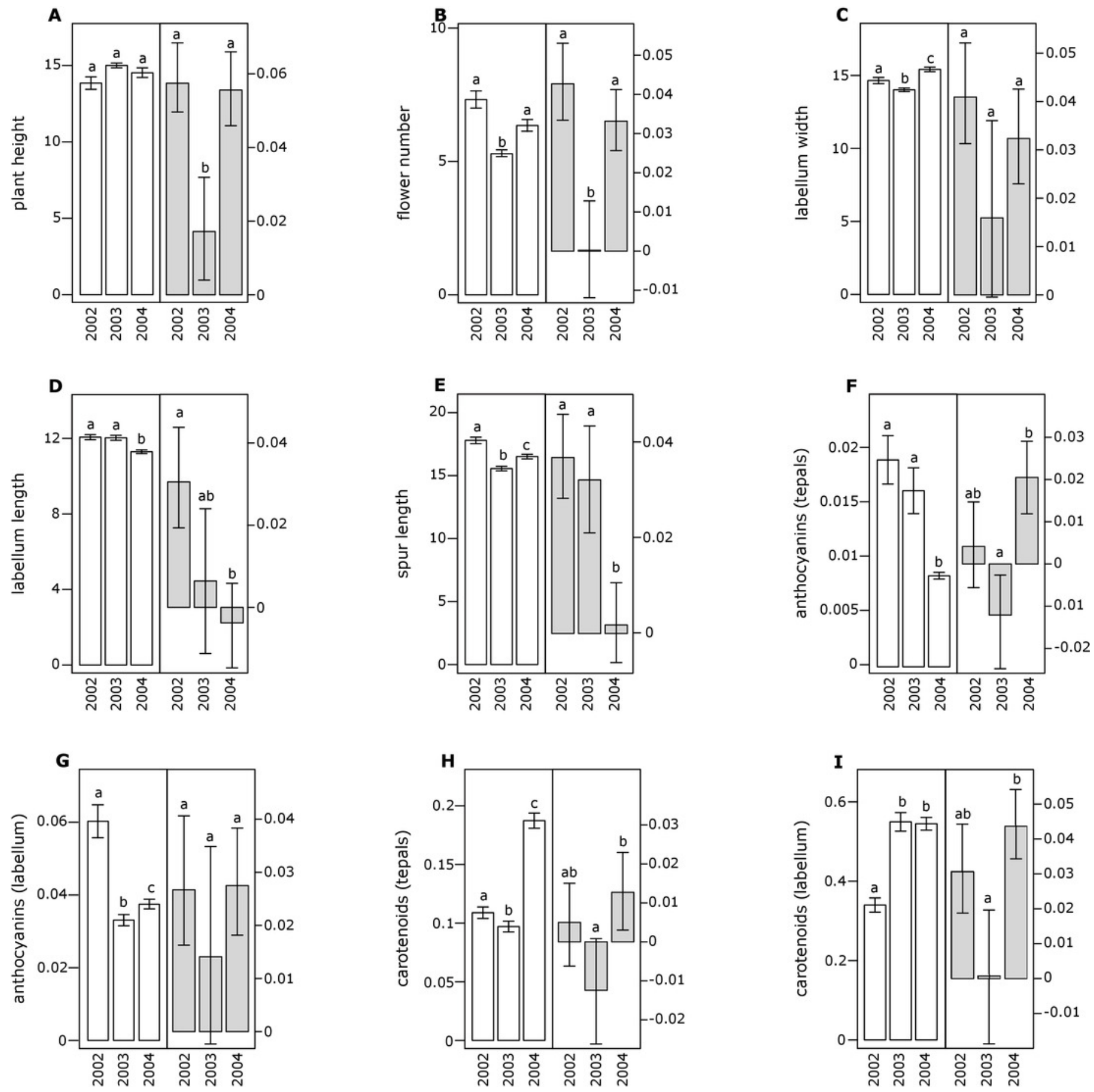


\section{Table $\mathbf{1}$ (on next page)}

Phenotypic Correlations

Phenotypic Correlations (Spearman's rank) among morphological traits in Orchis mascula (above diagonal) and $O$. pauciflora (below diagonal). All plants from the three years were pooled together. 
Table 1 Phenotypic Correlations (Spearman's rank) among morphological traits in Orchis mascula (above diagonal) and $O$.

\begin{tabular}{|c|c|c|c|c|c|c|c|c|c|}
\hline & $\begin{array}{l}\text { Plant } \\
\text { heigth }\end{array}$ & $\begin{array}{l}\text { Flower } \\
\text { number }\end{array}$ & $\begin{array}{l}\text { Labellum } \\
\text { width }\end{array}$ & $\begin{array}{l}\text { Labellum } \\
\text { length }\end{array}$ & $\begin{array}{l}\text { Spur } \\
\text { length }\end{array}$ & $\begin{array}{l}\text { Anthocyanins } \\
\text { content in } \\
\text { tepals }\end{array}$ & $\begin{array}{c}\text { Anthocyanins } \\
\text { content in } \\
\text { labellum }\end{array}$ & $\begin{array}{l}\text { Carotenoid } \\
\text { content in } \\
\text { tepals }\end{array}$ & $\begin{array}{c}\text { Carotenoid } \\
\text { content in } \\
\text { labellum }\end{array}$ \\
\hline Plant heigth & & $0.76^{\star \star *}$ & $0.47^{* * *}$ & $0.48^{\star * *}$ & $0.44^{* * *}$ & $0.29^{* \star *}$ & $0.25^{\star \star *}$ & 0.07 & -0.07 \\
\hline Flower number & $0.51^{* * *}$ & & $0.25^{\star * *}$ & $0.30^{* * *}$ & $0.24^{* * *}$ & $0.15^{\star *}$ & $0.14^{* *}$ & $0.15^{\star *}$ & 0.06 \\
\hline Lebellum width & $0.32^{* * *}$ & $0.28^{* * *}$ & & $0.71^{* * *}$ & $0.69^{* * *}$ & $0.39^{* * *}$ & $0.48^{* * *}$ & $-0.16^{\star *}$ & -0.09 \\
\hline Labellum length & $0.26^{* * *}$ & $0.22^{* * *}$ & $0.49^{* * *}$ & & $0.63^{* * *}$ & $0.40^{* * *}$ & $0.50^{* * *}$ & 0.01 & 0.06 \\
\hline Spur length & $0.22^{* * *}$ & $0.10^{*}$ & $0.44^{* * *}$ & $0.14^{* \star}$ & & $0.47^{* * *}$ & $0.50^{* * *}$ & -0.05 & -0.05 \\
\hline $\begin{array}{l}\text { Anthocyanins } \\
\text { content in tepals }\end{array}$ & $0.16^{* *}$ & $0.19^{* * *}$ & 0.08 & $0.22^{* * *}$ & 0.01 & & $0.66^{* * *}$ & -0.01 & -0.08 \\
\hline $\begin{array}{l}\text { Anthocyanins } \\
\text { content in }\end{array}$ & & & & & & & & & \\
\hline labellum & $0.18^{* * *}$ & $0.42^{* * *}$ & $0.31^{* * *}$ & $0.24^{* * *}$ & 0.08 & 0.45 & & -0.01 & 0.01 \\
\hline $\begin{array}{l}\text { Carotenoid } \\
\text { content in tepals }\end{array}$ & $-0.09^{*}$ & $0.21^{* * *}$ & $0.19^{* * *}$ & -0.03 & -0.05 & -0.05 & $0.18^{* * *}$ & & $0.43^{* * *}$ \\
\hline $\begin{array}{l}\text { Carotenoid } \\
\text { content in }\end{array}$ & & & & & & & & & \\
\hline labellum & $0.24^{* * *}$ & $0.19^{* * *}$ & $0.30^{* * *}$ & $0.10^{*}$ & 0.00 & $0.18^{* * *}$ & $0.25^{* * *}$ & $0.32^{* * *}$ & \\
\hline
\end{tabular}




\section{Table 2 (on next page)}

Selection gradients (ß) calculated according to Lande and Arnold (1983).

Significant estimates are in bold $(* * *, \mathrm{P}<0.001 ; * *, \mathrm{P}<0.01 ; *, \mathrm{P}<0.05$.$) .$ 
1 Table 2 Selection gradients (ß) calculated according to Lande and Arnold (1983). Significant

2 estimates are in bold $\left({ }^{* *}, \mathrm{P}<0.001 ;{ }^{* *}, \mathrm{P}<0.01 ;{ }^{*}, \mathrm{P}<0.05\right.$.)

\begin{tabular}{|c|c|c|c|c|c|c|}
\hline & \multicolumn{3}{|c|}{ Orchis mascula } & \multicolumn{3}{|c|}{ Orchis pauciflora } \\
\hline & 2002 & 2003 & 2004 & 2002 & 2003 & 2004 \\
\hline Plant height & -0.203 & 0.173 & 0.196 & 0.281 & 0.135 & $0.414^{* *}$ \\
\hline Labellum width & -0.231 & 0.018 & $-0.258^{*}$ & -0.040 & 0.017 & $0.295^{*}$ \\
\hline Labellum length & $0.462^{* *}$ & 0.070 & $0.538^{* * *}$ & 0.005 & 0.101 & $-0.411^{* * *}$ \\
\hline $\begin{array}{l}\text { Anthocyanin content in } \\
\text { tepals }\end{array}$ & 0.172 & -0.033 & 0.150 & -0.038 & -0.080 & 0.039 \\
\hline $\begin{array}{l}\text { Anthocyanin content in } \\
\text { labellum }\end{array}$ & 0.084 & 0.028 & -0.102 & 0.184 & 0.095 & 0.030 \\
\hline Carotenoid content in tepals & 0.066 & $0.245^{\star *}$ & -0.119 & 0.030 & -0.016 & -0.054 \\
\hline $\begin{array}{c}\text { Carotenoid content in } \\
\text { labellum }\end{array}$ & 0.149 & -0.062 & 0.021 & 0.005 & -0.018 & 0.187 \\
\hline
\end{tabular}

3 